Studia UBB 㚼igitalia, Volume 63 (LXIII) 2018, December, Issue 2, 65-83

Published Online: 2018-12-30

DOI:10.24193/subbdigitalia.2018.2.05

\title{
PANTHEON 3D. \\ An Initiative in the Three-Dimensional Digitization of Romanian Cultural Heritage
}

\author{
Anca Timofan, Călin Șuteu*, Radu Ota, George Bounegru, \\ Lascu Ilie, Radu Ciobanu, Dan Anghel, \\ Cătălin Pavel, Daniela Burnete
}

The National Museum of the Union Alba Iulia, *Gigapixel Art S.R.L.

\begin{abstract}
The Pantheon 3D cultural programme is the most ambitious initiative in the field of new technologies applied to archaeological heritage carried out by the National Museum of Unification in Alba lulia, one of the few at national level. In concept, the programme aims to render valuable the Roman artefacts belonging to the museum, using interdisciplinary methods. Via modern technologies and 3D documentation, Roman art works are digitized with the goal of accomplishing a virtual collection and a 3D interactive platform. The Pantheon 3D exhibitions and publications offer examples of three-dimensional models using specific techniques of non-textured rendering of surfaces, useful within studies of art history and as virtual models for artistic and iconographic interpretation.
\end{abstract}

Keywords: 3D digitization; 3D scanning; 3D printing; cultural heritage; cultural programme; Roman art; Apulum; virtual collection; interactive exhibition

\section{Introduction}

The current article aims to get readers intorduced to an exciting project implemented within the National Museum of Unification in Alba lulia by a group of specialists ${ }^{1}$ (archaeologists, conservators/restorers) and their collaborators and partners. The museum

\footnotetext{
${ }^{1}$ The Pantheon 3D team: Anca Timofan, Călin Șuteu, Radu Ota, George Bounegru, Ilie Lascu, Radu Ciobanu, Dan Anghel, Cătălin Pavel, Daniela Burnete, Adina Bogdan (English translator), Gabriela Cristina Balica (English translator).
} 
counts among the most important museum institutions in Romania, considering both its heritage and scientific prestige. It is also involved in numerous cultural activities, spanning from research and all the way to the protection and conservation of the national heritage. The Museum's collections contain valuable pieces of Roman art from Dacia, but also from the Hellenised area of Asia Minor. These are artefacts originating from Apulum (ancient Alba lulia), the largest Roman site of the province of Dacia.

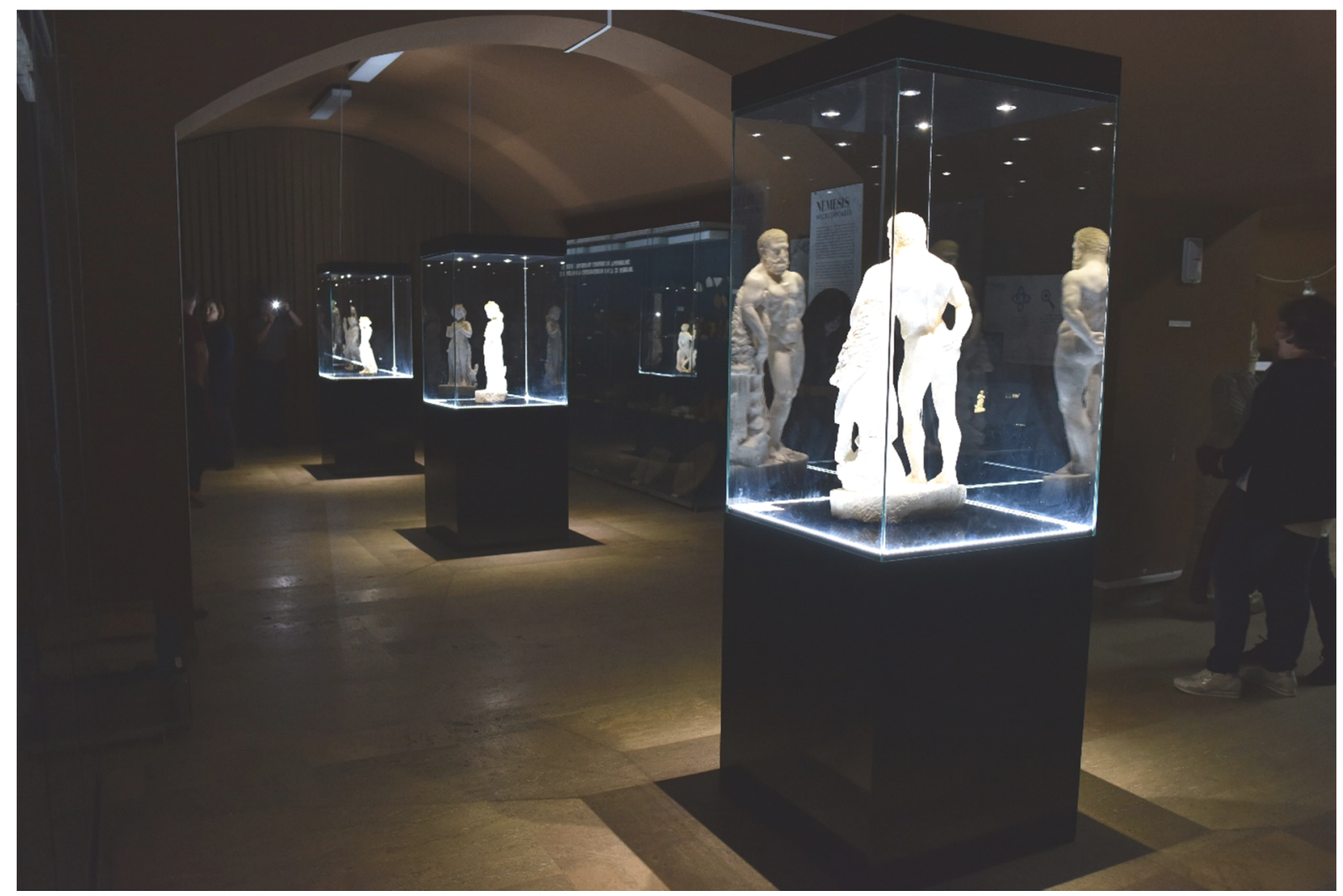

Fig. 1. Museum's permanent exhibition (Roman art collection)

\section{About the programme}

The Pantheon 3D cultural programme aims at the interdisciplinary enhanced use of Roman archaeological heritage through modern technology: 3D digitizing of the Roman artworks depicting deities and mythological figures in the collection of the National Museum of Unification in Alba Iulia, the accomplishment of a virtual collection and an interactive 3D platform, but also via the classical methods: temporary exhibitions on the topic of Roman religion and art at Apulum, publications, papers and workshops for pupils and students. 
Pantheon $3 D$ has been declared a winning project in the funding session of the National Cultural Fund Administration (AFCN) I/2018 for the area of Multiannual Programmes, to be implemented by the National Museum of Unification from Alba lulia over 2018 - 2019.

The enhanced use of the mobile cultural heritage through digital technology in the context of inter/multi-disciplinary approaches brings to the forefront the 3D scanning and photogrammetry as independent documenting methods, which may be though easily integrated in the flow of documenting operations specific to the cultural heritage.

The museum objectives of the programme consider the insertion of the new digital technologies in museum language and in the exhibition design, with the aim of improving contact with the visiting public. Facilitating access to the heritage for the wide audience is one of the specific objectives of the programme. Thus, the proposed activities target the setting of an information technology infrastructure by the accomplishment of an interactive platform - a virtual exhibition that allows access to the information existent in the database, the exhibition of the replicas of Roman art pieces that comes to the support of vision impaired persons.

The academic objectives aim at ensuring free access of the researchers to the scientific information and 3D digital technology applied to Roman artworks, by compiling the virtual collection for online use on the site of the National Museum of Unification in Alba lulia. This entails a generation of new study opportunities in the field of Roman art, by immediate access to this virtual collection that provides high precisions digital models, accompanied by technical, iconographical and bibliographical data.

Pantheon 3D activities are interdisciplinary and support the two methods of heritage valuation - classical and modern - thus generating mechanisms and durable processes, namely continuation and multiplication of results. For Romania, it is most certainly an important enterprise, with a very high potential of becoming a significant landmark on the market of cultural products, both regionally as well as at European level.

Pantheon $3 D$ counts among the projects in the field of the material, immaterial and digital cultural heritage developed in 2018 under the aegis of the European Year of Cultural Heritage, with the status of official event.

Within the Pantheon 3D cultural programme we established partnership with the following institutions: the City Hall of Alba lulia, the Babeș-Bolyai University of ClujNapoca, the "1 Decembrie 1918" University of Alba lulia, Brukenthal National Museum of Sibiu, the Museum of Dacian and Roman Civilisation of Deva, the History Museum of Turda, the "Regina Maria" Arts High School Alba lulia, the "Horea, Cloșca și Crișan" National College Alba lulia and the Romanian Association of the Blind - County Branch of Alba. 


\section{The cultural heritage and three-dimensional digitization}

The interest in the development of virtual aspects in the museum environment is increasingly obvious nowadays, with many efforts recorded in the last ten years being in the draft and development of those 3D technologies that would allow an as realistic as possible documenting and rendering of both mobile and immobile cultural heritage. Meanwhile, the concept of cultural heritage has become progressively more complex, hence the preservation - restoration operations have also implied more and more subjects, the correlation and interpretation of resulted data being ever more important in the adequate use of the provided potential. The new IT technologies, databases and the Internet make now possible improved coordination and integration of various data types resulting from these coordinated efforts.

Consequently, record and documenting methods and information management have become key pieces within the decision processes whose topic is cultural heritage, being entirely integrated to research, investigation, treatment and monitoring activities. Important advances have been recently registered also in the sphere of survey, documenting and enhanced use means, as well as in the field of conservation and restoration. Thus, new methods for data collection, new sensors, visualising equipment and interaction platforms have been created.

If the traditional documenting of mobile cultural heritage through photographs and drawings has been not until long ago sufficient for the efforts of the scientific community, one may presently speak of a true revolution in visual rendering and analysis, boosted by significant advances of digital technologies. Within this context, the computational photography documentation and structured light 3D scanning are two techniques that put at the disposal of academics, but also of the wide audience, interactive three-dimensional products easily disseminated in the on-line environment. Such digital representations have gradually replaced in research and education milieus (museum included), the classical photographs, drawings and films, bi-dimensional products lacking in most cases high precision and interactivity.

The field of computational photography, chiefly digital, as well as the computer processing currently work together in order to create solutions for an as complex as possible three-dimensional rendering of the surfaces and textures of heritage objects but also of archaeological monuments and sites, significantly contributing to specialty documenting. In parallel, there is notable increased attractiveness of museum collections in the eyes of the public of every age. In completion, the structured light 3D scanning 
method has been recently playing an important role in the quick high precision digitizing of museum collections, a conclusive example being provided precisely by the Pantheon $3 D$ cultural programme as well.

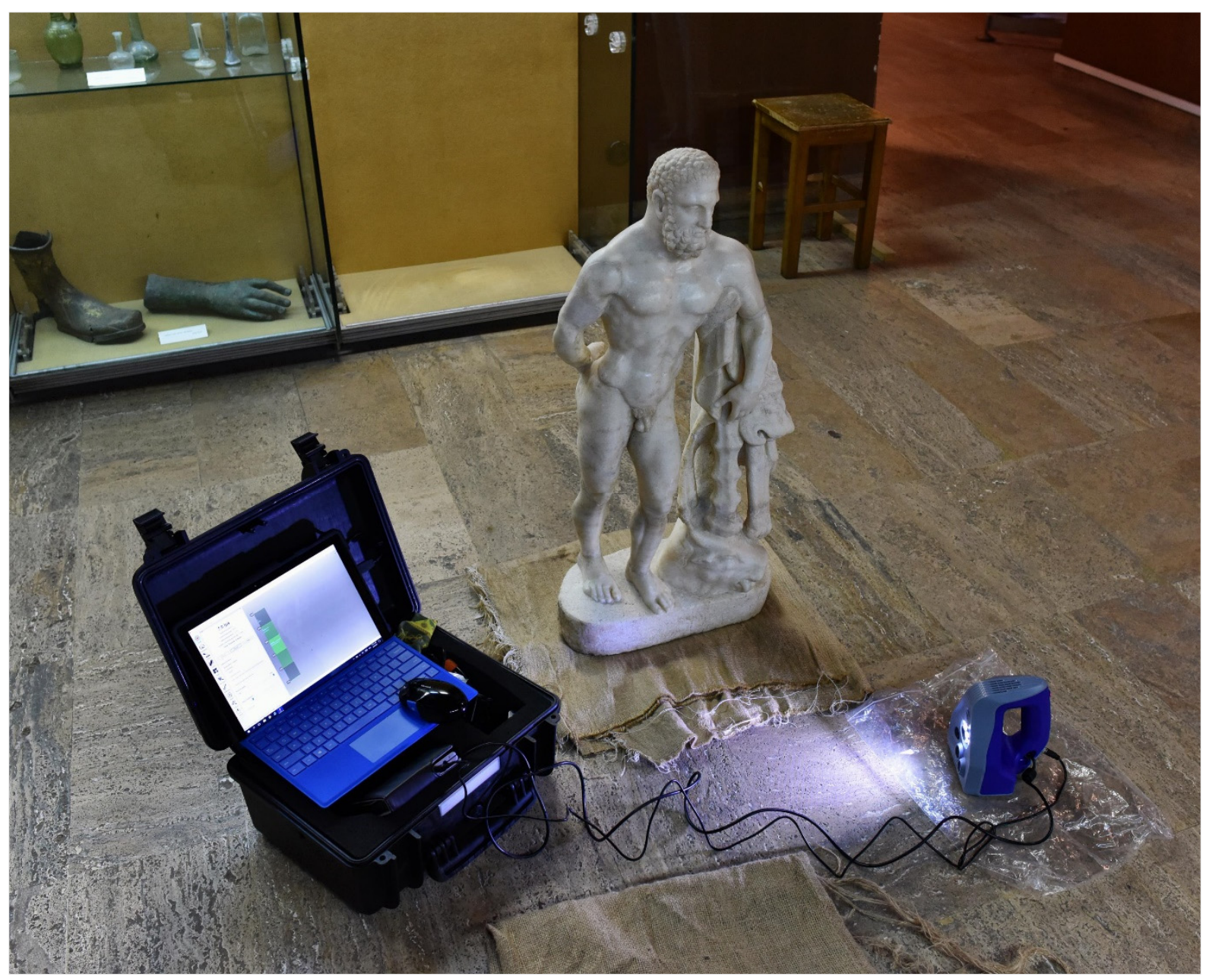

Fig. 2. Preparing the statuette of Hercules for 3D scanning

The documenting and enhanced use of the mobile heritage via the threedimensional technologies, are very well defined in the ensemble of the digitizing operations with the goal of protecting and rendering valuable the cultural heritage at worldwide level. 


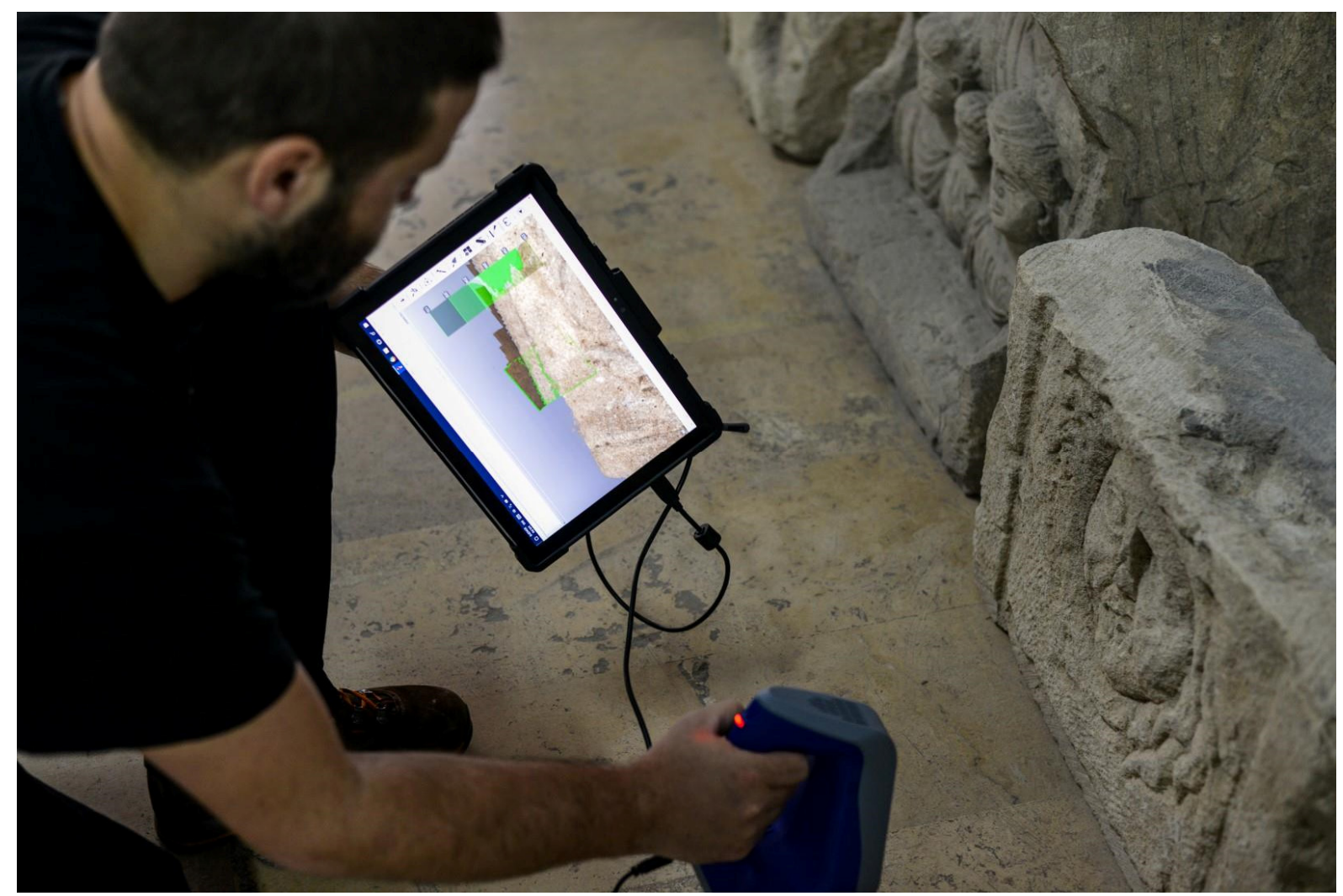

Fig. 3. 3D scanning Medusa's head on a Roman funerary monument

\section{Structured light scanning of the artefacts}

Recently, there has been intensified use of active sensors, laser and structured light in the three-dimensional documenting of cultural heritage objects, such high resolution and accuracy data being thus able to be disseminated for the interest of both scientific research and the broader audience, through museum and online enhanced use. The projection on an object's surface of a very narrow light strip produces at its turn a lighted line that seems distorted from any view other than its source, thus allowing, via several calibrated digital cameras to geometrically reconstruct the surface of respective object. A more versatile method is the projection of a complex network of such strips by using laser projectors, thus allowing registration of a very high number of data regarding the object's surface, with remarkable accuracy and in a short period of time. Compared to the passive method of photogrammetry, these sensors supply direct 3D information on the surface of the scanned object, in the form of point clouds. 
The precision of the system we used, the Artec SpaceSpider scanner, is of metrological order, down to $0.05 \mathrm{~mm}$, the generated 3D patterns being used in both applications of virtual museum type and detailed analysis of researched surfaces, high precision measurements etc. This scanner type may be used on various objects of different sizes, with the mention, that at this level of detail, the processing of large data sets may turn problematic. Thus is collected detailed information on the geometry, volume, colour and texture of the surfaces of an object without any effective contact, the result consisting in a graphic, digital rendering of their three-dimensional physical structure, a virtual surrogate.

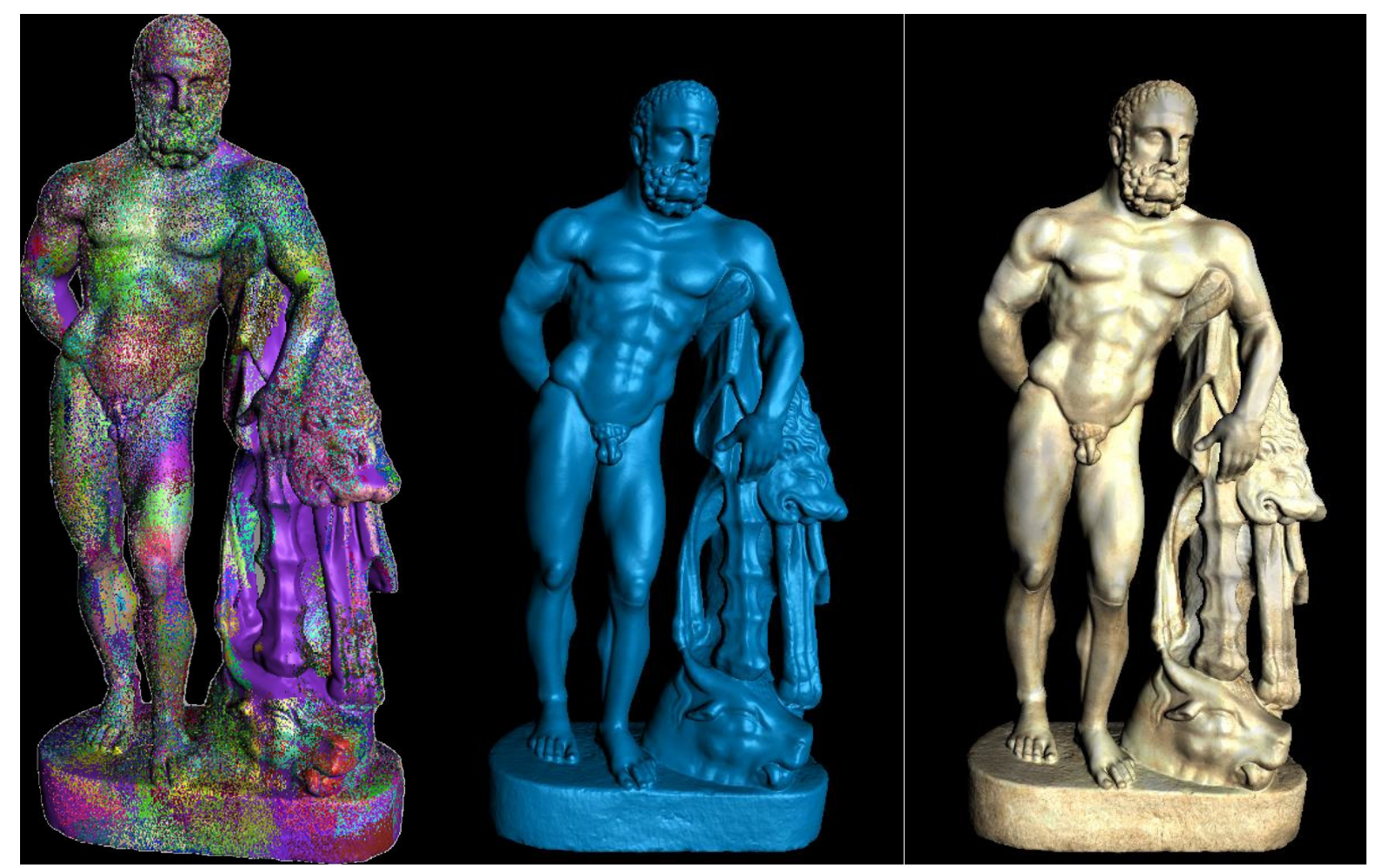

Fig. 4. Aspects from the processing of $3 D$ structured light scan data.

a) individual scans by color; b) final rendering (mesh); c) final rendering (mesh + texture)

\section{D Printing for museums, research and education}

The Pantheon 3D programme sets out, in a first phase, to answer a specific need to optimize the degree of public interaction with the classical museum environment, bringing into use new ways to exhibit, based exclusively on the latest technologies available 
from 3D scanning and printing. If our digital interactive on-line exhibition answers a first requirement towards interactivity and diffusion, both towards the public and the scientific environments, 3D printing comes to put forward a consistent message, facilitating direct tactile interaction with archaeological heritage artefact replicas, thus ensuring access to those visually impaired, most often forgotten by the classical museum display.

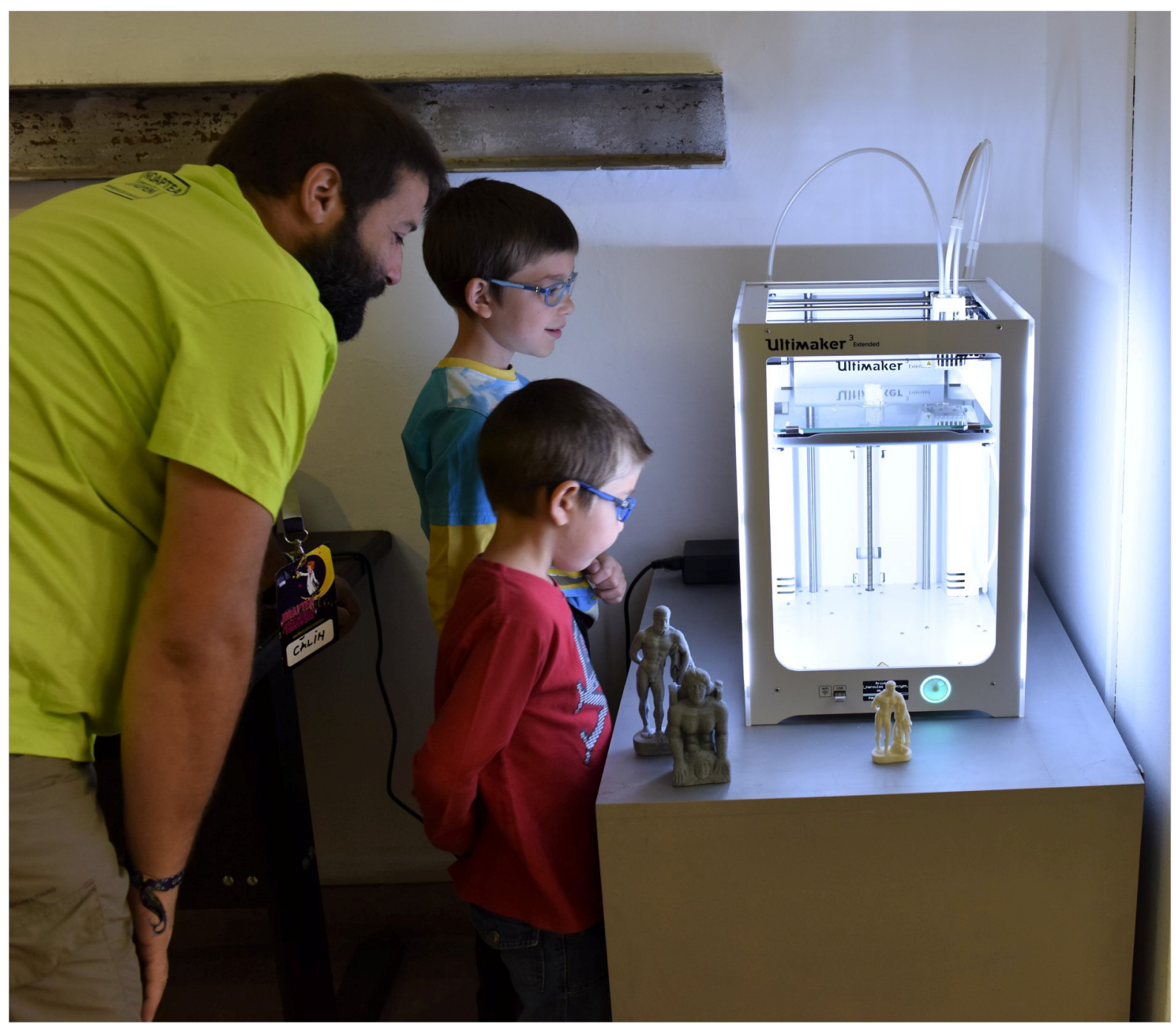

Fig. 5. Kids seeing a 3D printer for the first time (European Researcher's Night 2018 at the National Museum of Unification from Alba lulia) 
We can identify an entire series of advantages derived from using 3D scanning and printing in museum sciences and archaeological research, from documenting the smallest detail to three-dimensional archiving of contexts and artefacts that are threatened by the passage of time (erosion, etc.) and by conflict or natural disasters, all the way to consistently improving accessibility of collections. These technologies can also be used to replicate or complete damaged artefacts, as part of specific conservation and restoration practices. Within this entire context, our Pantheon $3 D$ programme aims to create, in a first phase, accurate scaled copies of our most representative artefacts, to be used in facilitating tactile interaction, specially aimed at visually impaired people and not the least to children of all ages. These replicas can also be used within our museum and also as part of worldwide educational experiences, as subject of art history lessons for example, not excluding specific uses within the research community.

A next stage within our project is to attempt repairs and integration of 3D printed missing parts that can be perfectly applied to the existing surfaces, based on scientific information and/or clear analogies from those times. The entire operation starts with making sure that the $3 \mathrm{D}$ model is ready for printing, a main requirement being that it is holefree, with complete surfaces. With the use of dedicated software (Ultimaker Cura 3.6) this model is then imported, rotated and scaled for optimal printing, the resolution is selected and also the degree in which the interior of the print is filled in. If the model is complex, with isolated and suspended surfaces (such as an extended arm) it is necessary to generate and print a support structure to allow for a complete and high quality printing of these particular areas. This support structure will be created also by the printer, using the second printing head, fed with a special plastic that can be easily removed later The entire model and its created support structure is then fragmented into thousands of horizontal layers by the software and then each are delivered to the printer, one by one. The minimum thickness of a layer is $0.1 \mathrm{~mm}$ (with certain materials $0.06 \mathrm{~mm}$ can be achieved), the resulting surfaces being very smooth, almost flat. The 3D printing of a high resolution $(0.1 \mathrm{~mm}) 29 \mathrm{~cm}$ high version of Hercules marble statuette took 3 days, 16 hours and 55 minutes to complete, using 37 meters (296 grams) of PLA filament and 21 meters (165 grams) of break-away filament. 


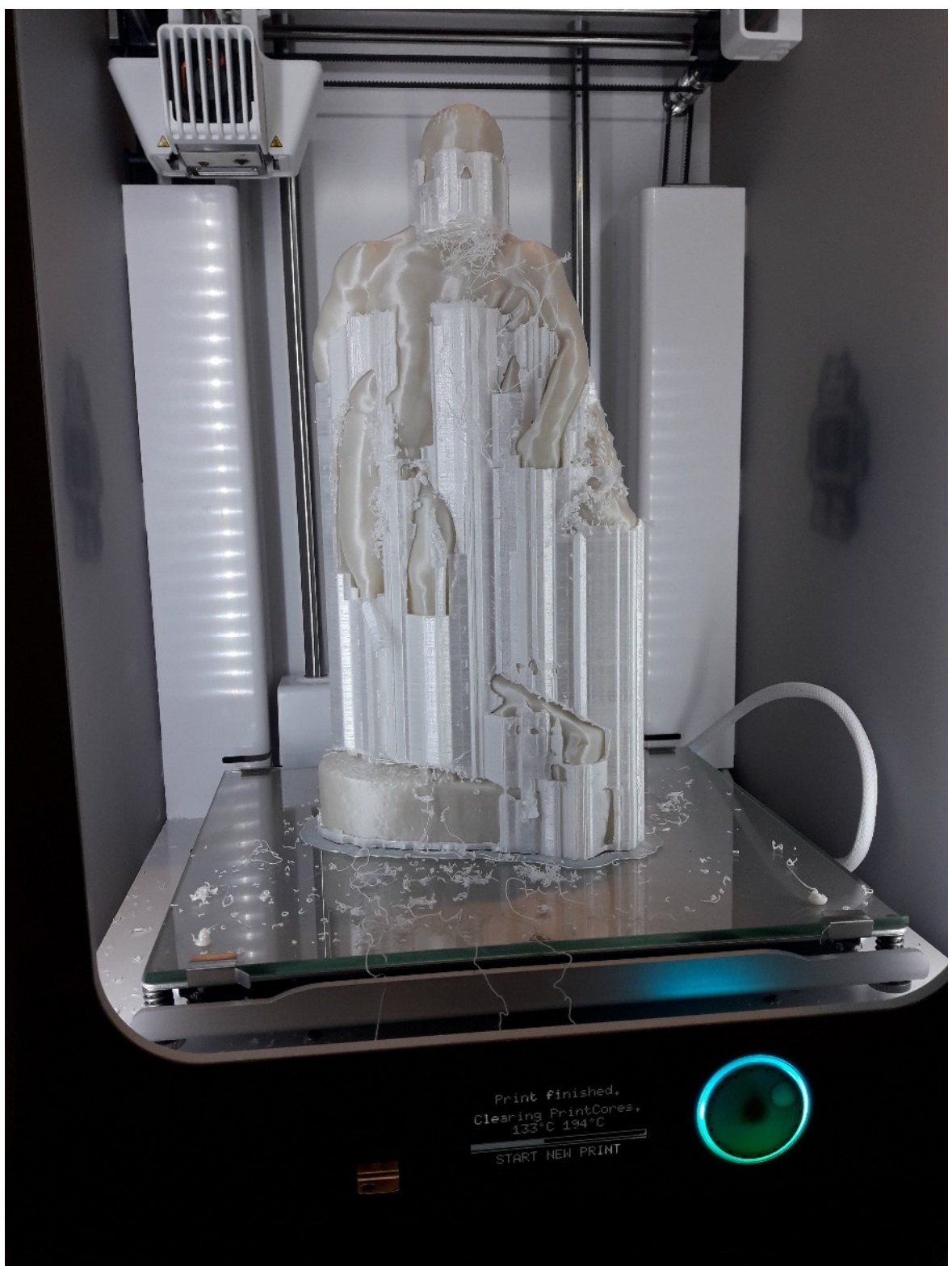

Fig. 6. 3D printing Hercules

Replicating artefacts with 3D printing and providing access to an online virtual museum could become essential steps into changing the perspective of museum environments, by restoring some essential aspects into the cultural experiences provided, like tactile and multi-sensorial interaction. 


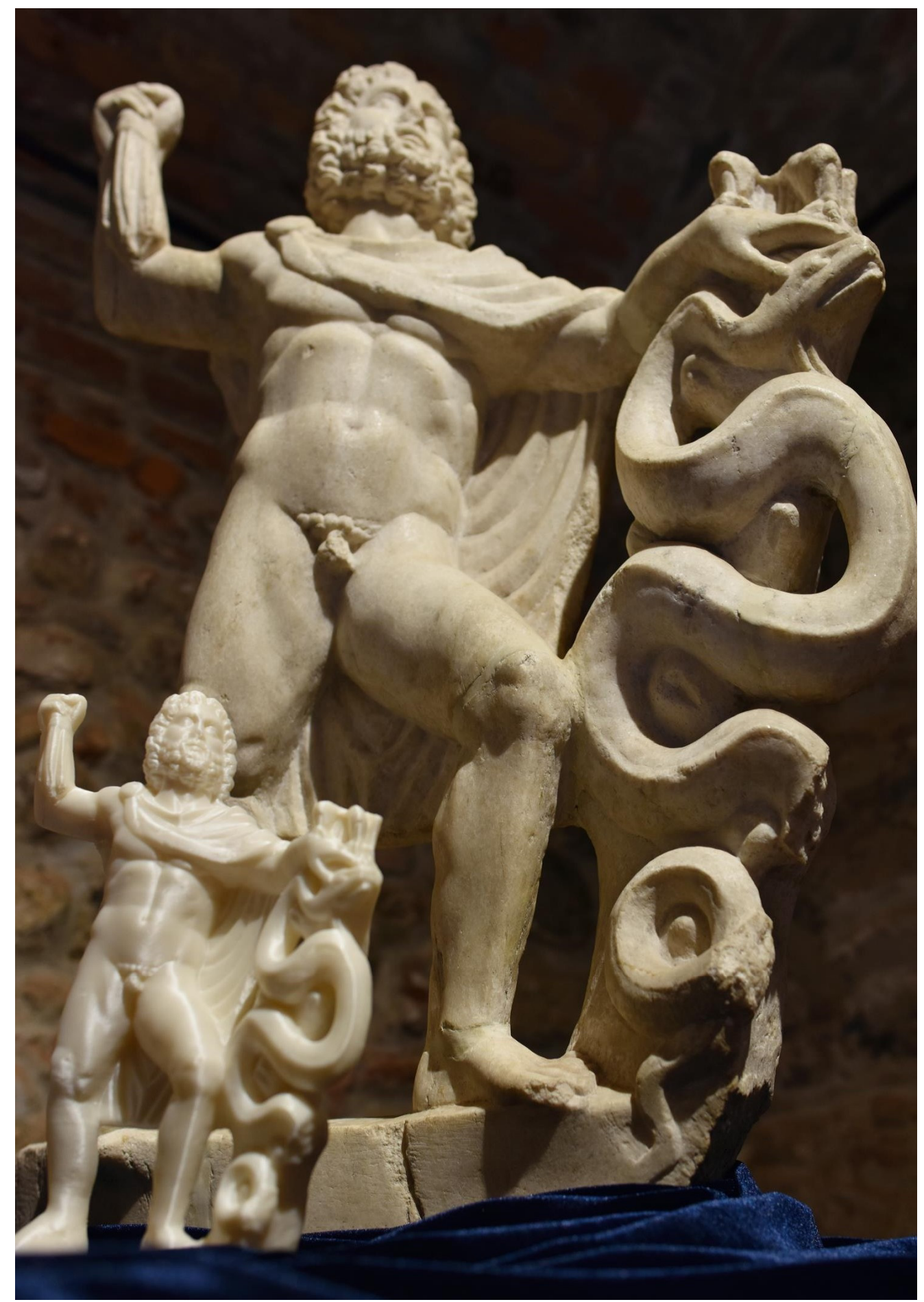

Fig. 7. Jupiter Zbelsurdos - the Roman original and its 3D replica 


\section{Pantheon 3D exhibitions and the virtual collection}

During 2018, the Pantheon 3D programme hosted several activities at The Night of Museums and The European Researchers' Night. The most important events were the two themed temporary exhibitions: MYTHOLOGY $3 D$ and MYSTERION 3D.

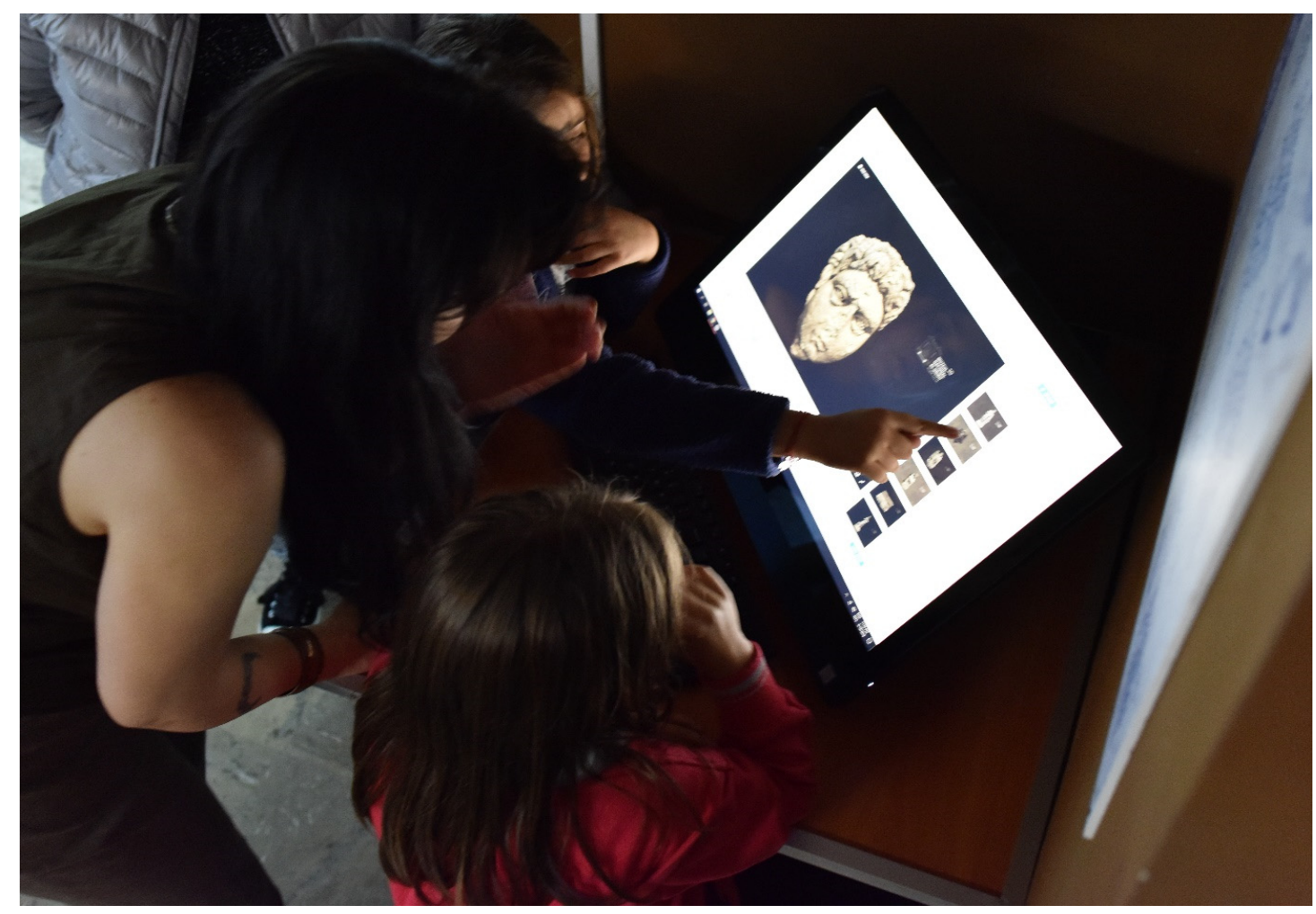

Fig. 8. Pantheon 3D at The Night of Museums 2018

MYTHOLOGY 3D. GRECO-ROMAN MYTHS - CLASSICAL AND MODERN ARTISTIC EXPRESIONS was the first exhibition held within the Pantheon 3D cultural programme. Its opening took place in May 2018, in the exhibition space of the Principia Museum, where the visitors journeyed to the mythical time of the Gods and Heroes of the Greco-Roman world. The exhibition featured pieces of Roman art depicting mythological figures and scenes from the Roman art collection of the National Museum of Unification in Alba lulia, most of them discovered in ancient Apulum. The exhibition concept has joined creatively and uniquely the Roman artworks with the classical mythological tales, with the artistic interpretation of the pupils with the "Regina Maria" Arts High School of Alba lulia. Subsequently, these works were presented within their graduation examination and put on display temporarily with the Art Gallery of Alba lulia. 


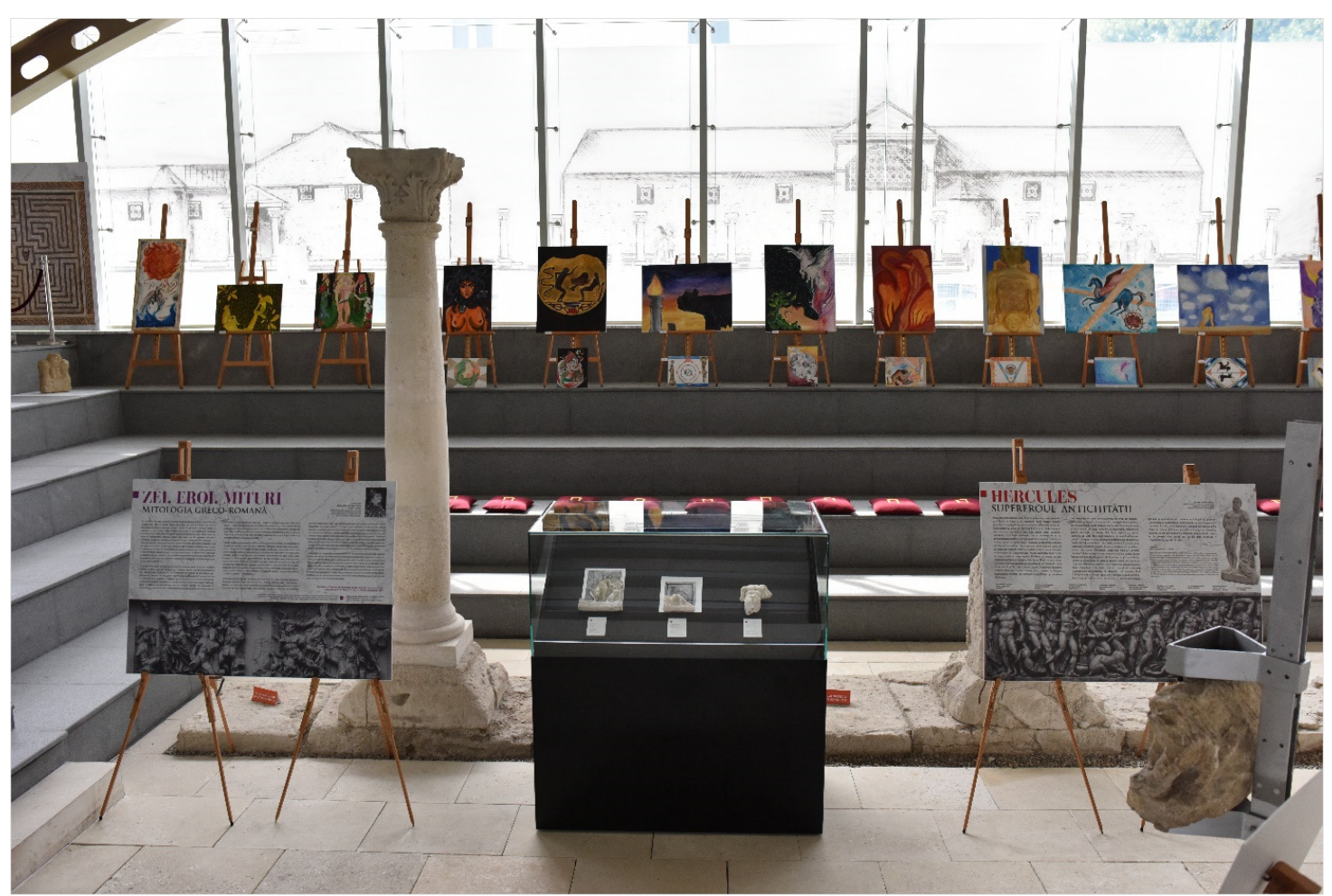

Fig. 9. Mythologia 3D at Principia Museum

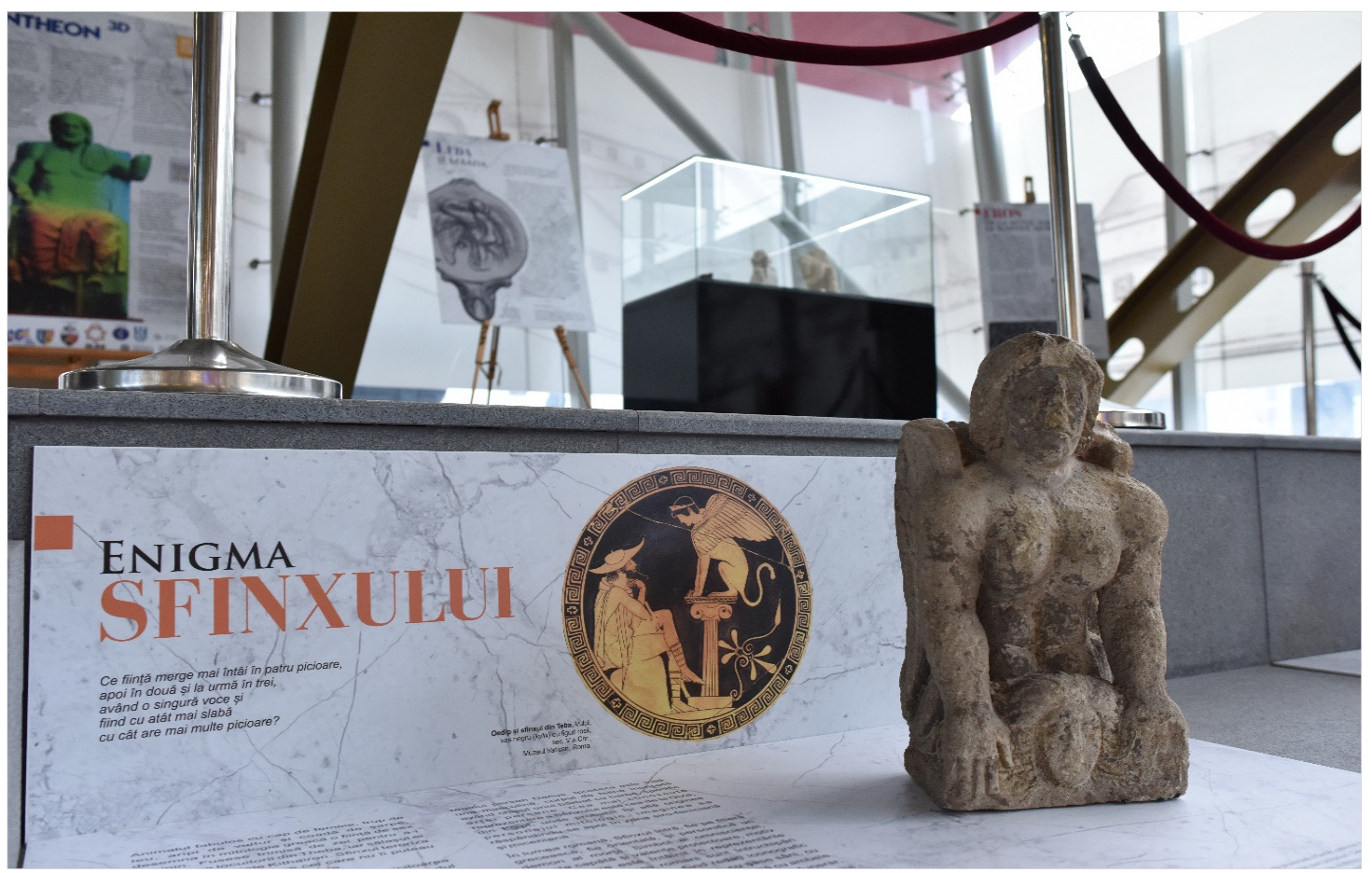

Fig. 10. Mythologia 3D 
The Pantheon $3 D$ series of events continued with an invitation into the hidden universe of the mystery cults in the ancient Greco-Roman world. The exhibition MYSTERION 3D. SAVIOR GODS, MYSTERIES AND RELIGIOUS SYNCRETISM AT APULUM opened at Museikon in November 2018. Visitors came into the atmosphere of an exhibition which combined the classic display of the museum's Roman art collection with the modern technology used in $3 \mathrm{D}$ digitization of the archaeological heritage of Apulum.

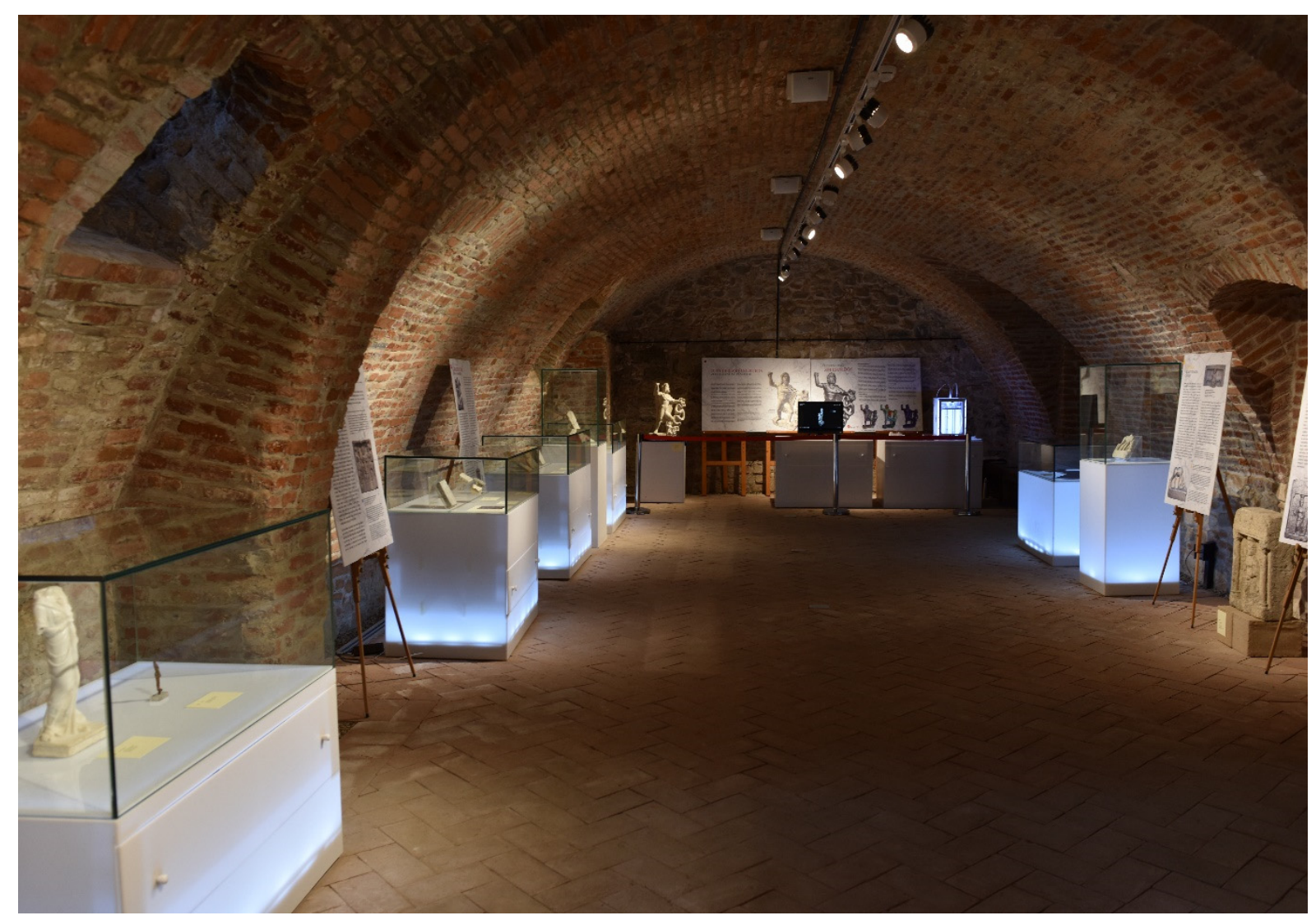

Fig. 11. Mysterion 3D at Museikon

Gods and goddesses with origins either in the extravagant Orient, or in the mythological traditions of the Thracians and Celts, have entered the pantheon of Apulum. They were part of a world marked by religious diversity and syncretic phenomena. Fascinating divinities, like Mithras, Isis or Serapis, were extremely popular in Antiquity, 
and their mysteries became religious trends. Numerous followers have been attracted by the orgiastic character of the ceremonies, or the esoteric nature of the initiation rituals and sacred liturgies (hieroi logoi). The savior and mystic gods promised the salvation of the soul, and were offering a positive perspective on life after death. Furthermore, their pantheist nature also recommended them as protectors, healers, and prosperity bearers.

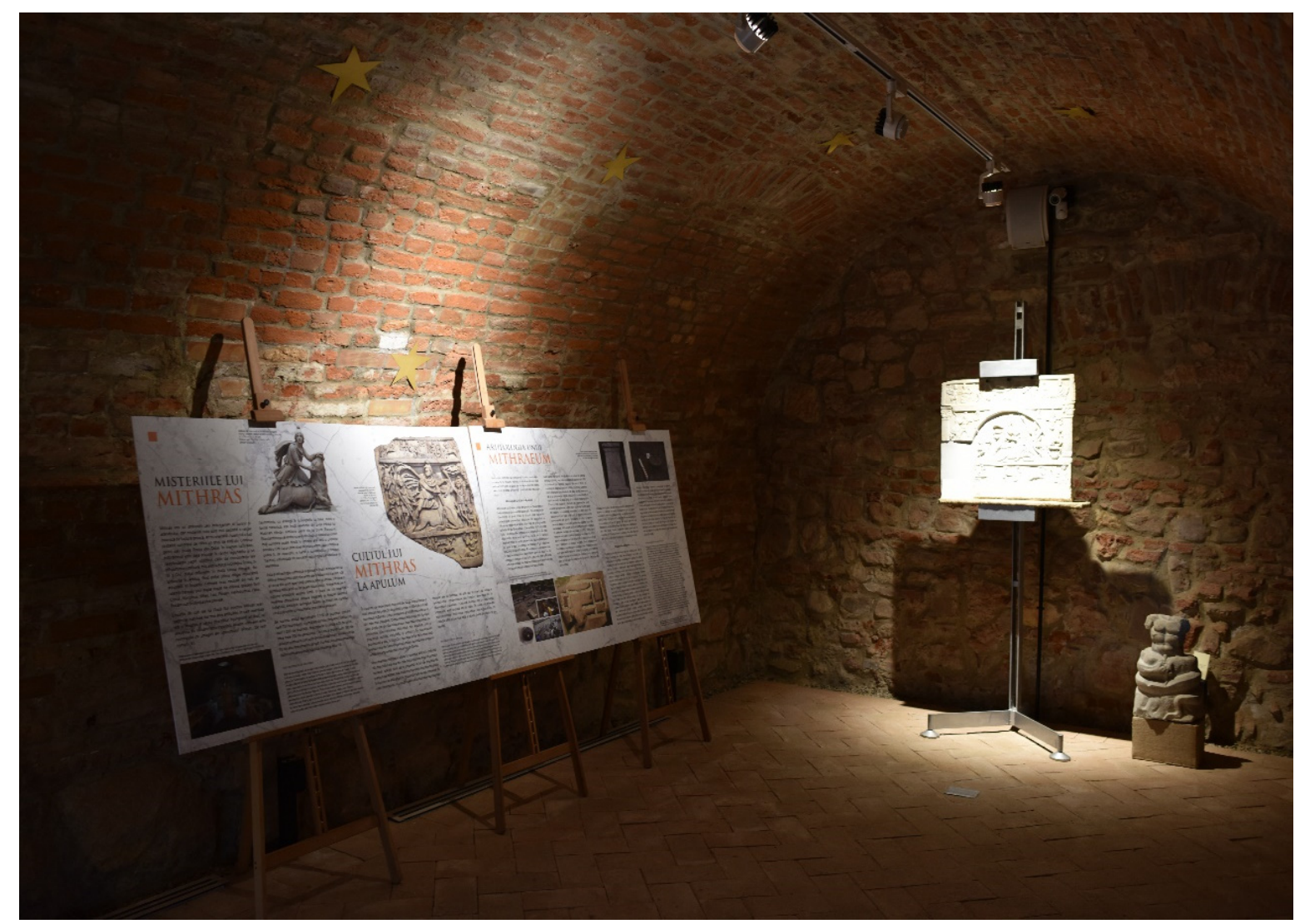

Fig. 12. Mysterion 3D. The Mithraeum

Mysterion 3D suggested a new initiation that is in the "mysteries" of 3D digitization. It is an introduction in the themes of an advanced method for the documentation, research, and virtual archiving of cultural heritage, a method which has been attracting more and more followers in the recent years. 


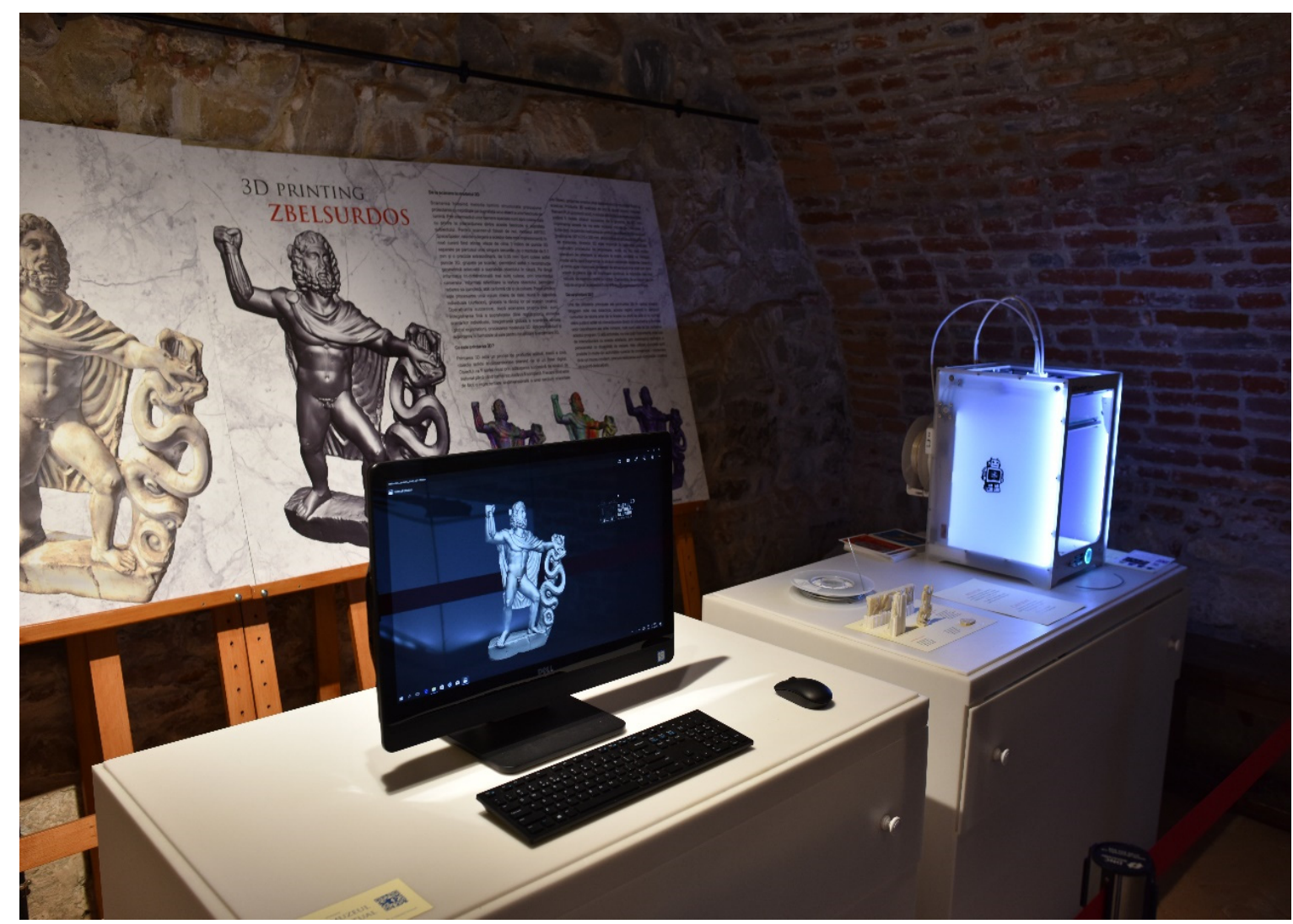

Fig. 13. Mysterion 3D. Jupiter Zbelsurdos 3D presentation

Each exhibition had an interactive 3D presentation. GODS ON DISPLAY was the $3 \mathrm{D}$ exhibition part for visualising the Roman artworks depicting gods and mythological figures. The presentation was made with the aid of an interactive device with touch screen which allowed the online access and visualising by the visiting public of the collection of Roman sculptures 3D models available at https://sketchfab.com/ MNUAI, through the platform Sketchfab.com. The Pantheon 3D virtual collection existing on Sketchfab includes until now the Roman art works from the National Museum of the Unification's heritage that were the subject of the two exhibitions. This virtual museum will be further developed as our programme will advance, with the aim of its integration in international and national digitizing programmes of the cultural heritage, like for instance the European Digital Library - Europeana.eu. 


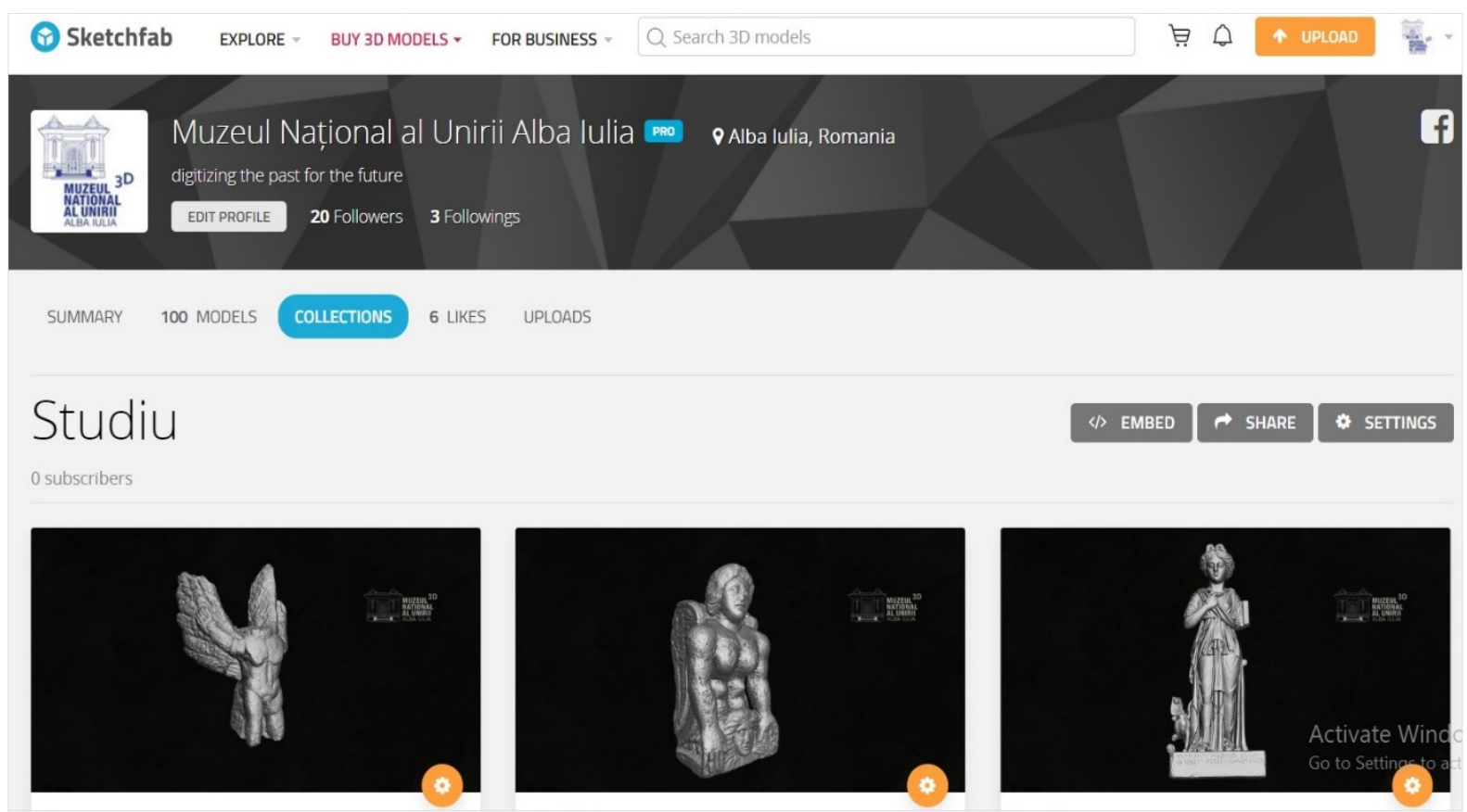

Fig. 14. The Museum's virtual collection on Sketchfab

\section{Pantheon 3D in the future}

Digital documenting of the tangible cultural heritage based on 3D scanning, modelling and printing may open the museum to the entire world. The importance of such initiatives is indisputable within the framework of urgent protection, recovery and restoration of cultural heritage measures in risk areas or in the context of catastrophes, like those in the Middle East or Brazil.

When we originally set forth, we imagined the aims of the Pantheon 3D programme, then in a draft form, as threefold: museum, educational and for research. Beside the necessity to integrate latest digital technologies in the concept of museum exhibition and use of the archaeological heritage, as well as in the conservation-restoration processes, the accomplishment of the 3D Digital Collection comprising pieces in the museum's heritage, a collection accessible online, represented an important aspect of our approach, while amongst the reasons, concerns related to possible critical situations did not lack.

Information technology and the image culture are aspects that acquire day by day an increasingly more important role in the educational field, in both education and museum milieus. To this effect, are required continued and sustained efforts to integrate new technologies as part of the educational act as well as attractive, even entertaining activities within museums. 


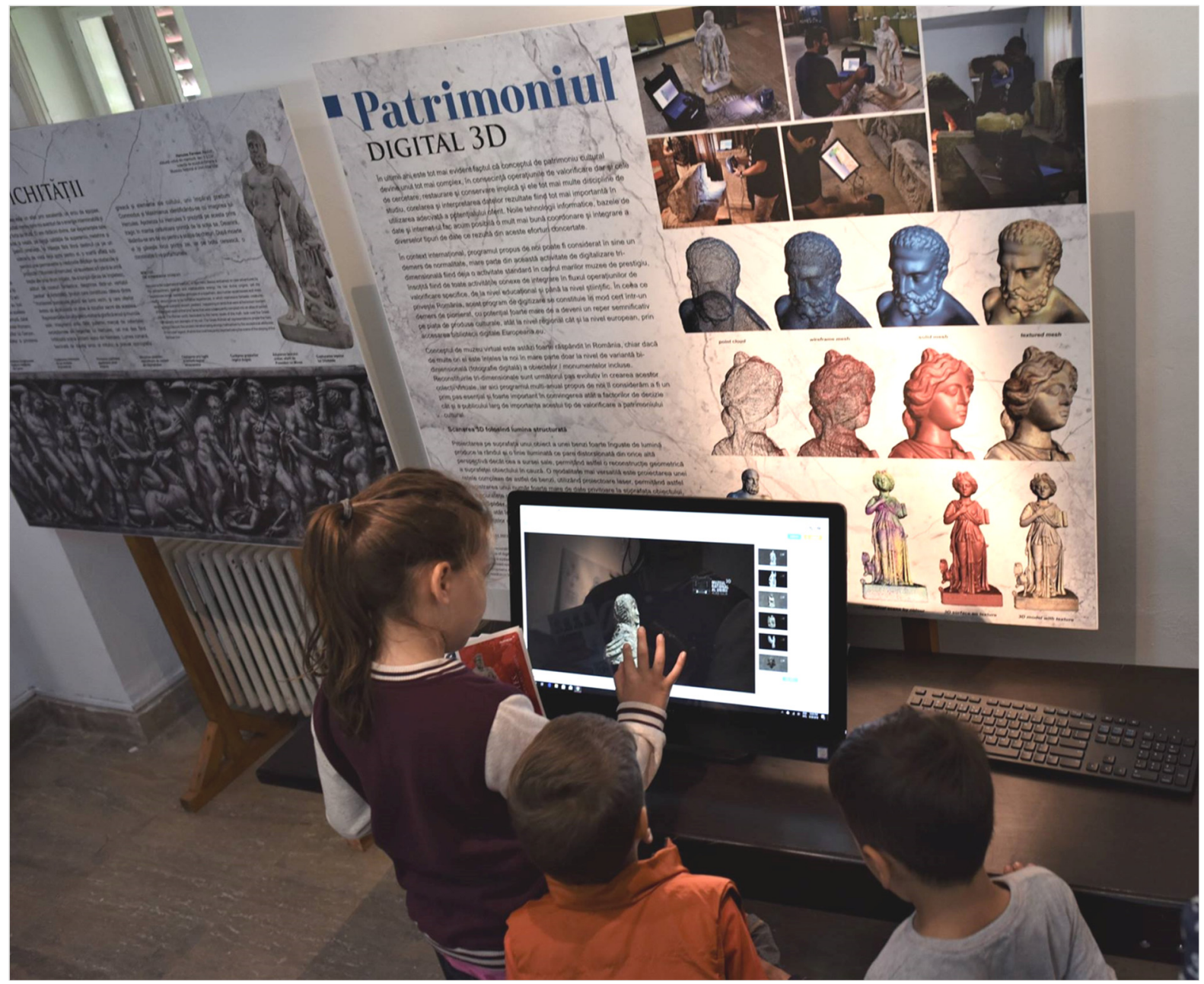

Fig. 15. GODS ON DISPLAY (European Researcher's Night 2018)

Through its purpose and objectives, the nature and structure of the activities, the interdisciplinary concept and the use of 3D technology, Pantheon 3D programme will be able to generate modern structures, platforms and resources (human and technological) that will ensure not only its continuity but also multiplication. The results and the products of the cultural programme are sustainable. The interactive digital platform using 3D technology can promote the museum heritage, and could be a model to be followed for new approaches in the use of cultural heritage.

The main element of sustainability and continuity in this case is the possibility of adding new pieces of museum collections and increasing their international visibility. Through its activities, Pantheon $3 D$ generates new and innovative cultural products 
that are the result of intelligent management of human resources involved in the program and the use of creativity in a space where artistic innovations blend harmoniously with modern digital technology. In an international context, the programme can be considered a normality in itself, since the three-dimensional digitization activity is already a standard activity in the museums.

\section{Bibliography}

The programme presentation and the information on 3D technology have been taken from the Pantheon $3 D$ volumes published so far:

Timofan, A. (ed.). Pantheon 3D I Mituri Greco-romane. Greco-Roman Myths. Mega, $2018 .^{2}$

Timofan, A. (ed.). Pantheon 3D II Zei Salvatori - Culte de mistere - Sincretism. Savior Gods - Mystery Cults - Syncretism. Mega, 2018. ${ }^{3}$

\footnotetext{
2 https://apulumarchaeology.files.wordpress.com/2018/11/pantheon-3d-vol-i-mituri-greco-romanegreco-roman-myths-editura-mega-cluj-napoca-2018.pdf

${ }^{3} \mathrm{https}$ ://apulumarchaeology.files.wordpress.com/2019/02/pantheon-3d.-vol.-ii-zei-salvatori-cultede-mistere-sincretism.-savior-gods-mystery-cults-syncretism-editura-mega-cluj-napoca-2018.pdf
} 